\title{
New perspectives for satellite-based archaeological research in the ancient territory of Hierapolis (Turkey)
}

\author{
R. Lasaponara ${ }^{1}$, N. Masini $^{2}$, and G. Scardozzi ${ }^{3}$ \\ ${ }^{1} \mathrm{CNR}$, Istituto di Metodologie per l'Analisi Ambientale, Tito Scalo (PZ), Italy \\ ${ }^{2} \mathrm{CNR}$, Istituto per i Beni Archeologici e Monumentali, Tito Scalo (PZ), Italy \\ ${ }^{3} \mathrm{CNR}$, Istituto per i Beni Archeologici e Monumentali, Lecce, Italy
}

Received: 28 August 2008 - Revised: 5 November 2008 - Accepted: 6 November 2008 - Published: 14 November 2008

\begin{abstract}
This paper deals with the use of satellite QuickBird images to find traces of past human activity in the ancient territory of Hierapolis (Turkey). This is one of the most important archaeological sites in Turkey, and in 1988 it was inscribed in the UNESCO World Heritage list. Although over the years the archaeological site of Hierapolis has been excavated, restored and well documented, up to now the territory around the ancient urban area is still largely unknown. The current research project, still in progress, aims to search the area neighbouring Hierapolis believed to have been under the control of the city for a long time and, therefore, expected to be very rich in archaeological evidence. In order to investigate a large area around the ancient Hierapolis and discover potential archaeological remains, QuickBird images were adopted.

Results from satellite-based analysis allowed us to find several unknown rural settlements dating back to early Imperial Roman and the Byzantine age. Two significant test sites were focused on in this paper in order to characterize the different spectral responses observed for different types of archaeological features (shadow and soil marks). Principal Component Analysis and spectral indices were computed to enhance archaeological marks and make identification easier. The capability of the QuickBird data set (panchromatic, multispectral channel, PCA and spectral indices) in searching for archaeological marks was assessed in a quantitative way by using a specific indicator.
\end{abstract}

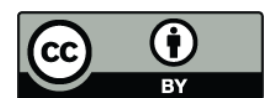

Correspondence to: R. Lasaponara (lasaponara@imaa.cnr.it)

\section{Introduction}

Over the years, investigation of archaeological heritage and ancient landscapes have been widely addressed by using remote sensing technologies, available from ground, air and space. Aerial photos and geophysical prospection have been the most common remote sensing data source used by archaeologists for detecting and mapping new sites. More recently, satellite remote sensing data from active and passive sensors have been adopted in archaeological context for searching for larger areas. Different imaging instruments have been applied to a wide range of archaeological investigations, such as, (i) Landsat Multispectral Scanner (MSS) and Temathic Mapper (TM) (Behnaz and Samani, 2006), (ii) SPOT (Clark et al., 1998), (iii) ASTER (Altaweel, 2005), (iv) CORONA (Goossens et al., 2006; Beck et al., 2007). Nevertheless, until the availability of the Very High Resolution (VHR) data, the application of multispectral satellite imagery for archaeological investigations was limited due to the low spatial resolution of early satellite sensors, such as Landsat MSS $(90 \mathrm{~m})$, TM $(30 \mathrm{~m})$, or Spot $(10 \mathrm{~m})$. The low spatial resolution did not provide sufficient precision to search for archaeological sites and obtain a detailed spatial characterization of subsurface or exposed ancient remains. For this reason, satellite imagery was generally applied to paleo-geographic environment studies, human ecology and landscape archaeology (Parry, 1992; Drake, 1997; Sheets and Sever, 1998; White and Asmar, 1999).

The current VHR satellite images with spatial resolutions comparable with those obtained from aerial photos is a cost effective technology for the identification of potential archaeological features, as well as for the documentation and the management of archaeological sites (Lasaponara and Masini, 2007; De Laet et al., 2006).

Published by Copernicus Publications on behalf of the European Geosciences Union. 


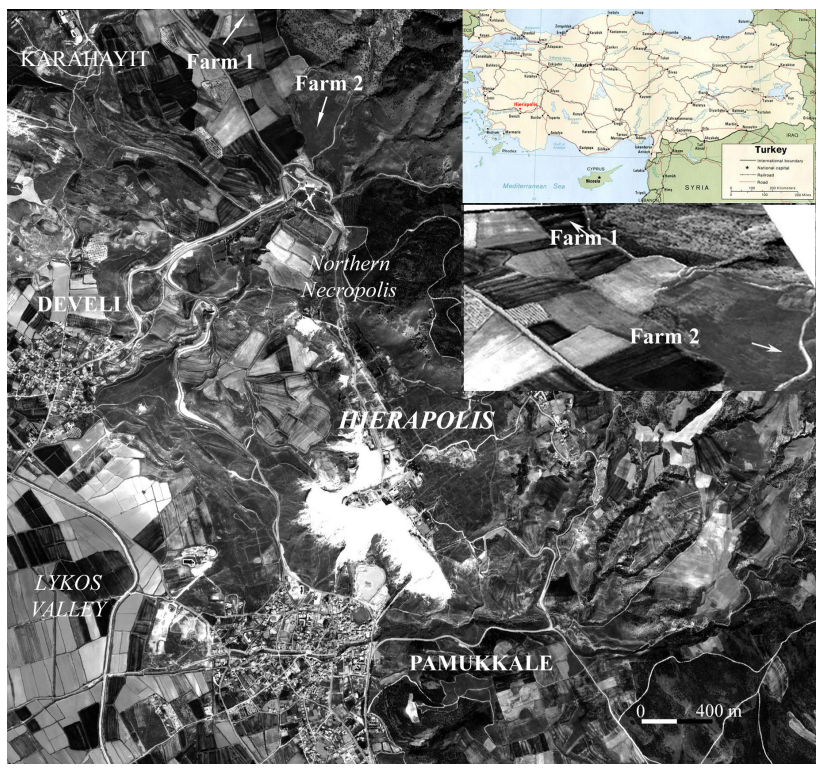

Fig. 1. Location of the study areas.

In this study, QuickBird data were used to support the archaeological research performed in the territory of Hierapolis of Phrygia (South west Turkey) which, up to now, has not been extensively or systematically investigated. Among the large amount of archaeological evidence revealed by the satellite data, two significant test sites were focused on in this paper. For both of them, a data fusion algorithm was applied to merge the spatial and spectral capability of QuickBird pancromathic and multispectral channels. Moreover, Principal Component Analysis (PCA) and spectral indices were also computed to further enhance archaeological marks and facilitate their identification.

\section{Study area}

The investigations were performed in two significant test areas located in the ancient territory of Hierapolis of Phrygia situated near Pamukkale and Denizli which are about $200 \mathrm{~km}$ East of Izmir (Fig. 1a). The ancient urban area stretches over a travertine shelf looking onto the broad and fertile valley of the Çürüksu, the ancient river Lykos, one of the tributaries of the Meander. The shelf rises steadily towards the East. On the western side there is a sharp drop towards the plain below. The steep slope is covered by white calcareous formations, produced by the springs whose waters emerge from the central area of the city.

Archaeological investigation identified four subsequent periods of the historical development of the city: (i) from its foundation in the 3rd century BC until the devastating earthquake in $60 \mathrm{AD}$, (ii) the Flavian period until the earthquake in the middle of the 4th century $\mathrm{AD}$, (iii) the early Byzantine period, and (iv) the last period after a destructive earthquake in the middle of the 7th century $\mathrm{AD}$, when Hierapolis went into decline.

Beginning in 1957 Hierapolis has been brought back to its ancient splendour (D'Andria, 2003) by the Italian Archaeological Mission (D'Andria and Caggia, 2007), which, over the years, has excavated and restored the ancient city and the surrounding large necropolises.

Since 2003 archaeological surveys based on the use of QuickBird panchromatic imagery have been in progress in the urban area (Scardozzi, 2007; D' Andria et al., 2008) and in the subsequent years (2005) has also extended to cover the neighbourhood of the ancient city (Scardozzi, 2007b).

In this paper we focused on (Fig. 1) the hilly relief on the North of Hierapolis and East of the village of Karahayit. This area has been characterized by an intense human activity as attested to by epigraphic sources (D'Andria, 2003).

\section{Quickbird satellite based analysis: data, rationale and tools}

\subsection{Data set}

The QuickBird data used for this study (Cata$\log$ ID:10100100041F7700) were acquired on the 25th March 2005 at 9 a.m. The QuickBird dataset, made up of one panchromatic at $0.6-\mathrm{m}$ resolution and four multispectral images (from blue to near infrared bands) at $2.4-\mathrm{m}$ resolution, were taken with an off nadir View Angle of 4.9 degrees, this assures a limited geometric distortion.

\subsection{Rationale basis and data processing}

Archaeological features can be described as geophysical and chemical spatial anomalies that tend to form geometric patterns according to the spatial morphology (structure and layout) of the exposed or buried archaeological remains. On the basis of their typical characteristics, archaeological marks are generally classified as (i) shadow-marks, (ii) soil marks, and (iii) crop marks.

1. Soil-marks can appear on bare soil as changes in colour, texture, grain size and/or moisture content.

2. Crop marks can be evident for vegetated areas, covered by crops or weeds. They can appear as differences in height or colour in crops/weeds which are under stress due to lack of water or deficiencies in other nutrients. They can be formed both as negative marks above wall foundations and as positive marks above pits and ditches (Wilson, 1982).

3. Shadow marks can be seen as variations in microtopographic relief. Such slight differences in ground levels tend to cast shadows when the sun is low. Such 
marks can be seen best if the satellite scene is acquired early (as in the case of Hierapolis) or late in the day.

The different marks linked to the presence of buried or exposed archaeological remains could be detected using satellite images by exploiting specific spectral channels or their numerical combinations (spectral indices).

According to soil spectral signatures, the Quickbird red channel has been found to be capable of revealing soil marks (Lasaponara and Masini, 2005). Whereas, according to the vegetation spectral behaviour, the Quickbird near-infrared (NIR) channel has been found to be capable of enhancing crop-marks (Lasaponara and Masini, 2007), as already verified for other satellite data (Fowler 2002).

Finally, the capability of Quickbird data to capture the presence of shadow marks is strongly dependent on the acquisition time of the satellite scenes. Early morning or late afternoon satellite pictures may capture the slight shadows originating from micro-topographic relief when the sun is low. The presence of micro-topographic relief, could be much more evident in the Quickbird panchromatic or red images (Lasaponara and Masini, 2005).

A significant improvement in enhancing buried and/or exposed ancient remains could be achieved by using different data processing techniques, such as Principal Component Analysis (PCA), spectral indices, and data fusion. Figure 2 shows the flow-chart we propose to enhance the archaeological features.

The PCA is a linear transformation which decorrelates multivariate data by translating and/ or rotating the axes of the original feature space, so that the data can be represented without correlation in a new component space (Richards, 1989). In order to do this, the process firstly computes the covariance matrix (S) among all input spectral channels, then eigenvalues and eigenvectors of $\mathbf{S}$ are calculated in order to obtain the new feature components.

$\operatorname{cov} k 1, k_{2}=\frac{1}{\mathrm{~nm}} \sum_{i=1}^{n} \sum_{j=1}^{m}\left(\mathrm{SB}_{i, j, k 1}-\mu_{k 2}\right)\left(\mathrm{SB}_{i, j, k 2}-\mu_{k 2}\right)$

where $k_{1}$ and $k_{2}$ are two input spectral channels, $\mathrm{SB}_{i, j}$ is the spectral value of the given channel in row $i$ and column $j, n$ is the number of rows, $m$ is the number of columns, $\mu$ is them ean of all pixel SB values in the subscripted input channels.

The percent of total dataset variance explained by each component is obtained by Eq. (2).

$\% i=100 * \frac{\lambda_{i}}{\sum_{i=1}^{k} \lambda_{i}}$

where $\lambda_{i}$ are the eigenvalues of $\mathbf{S}$.

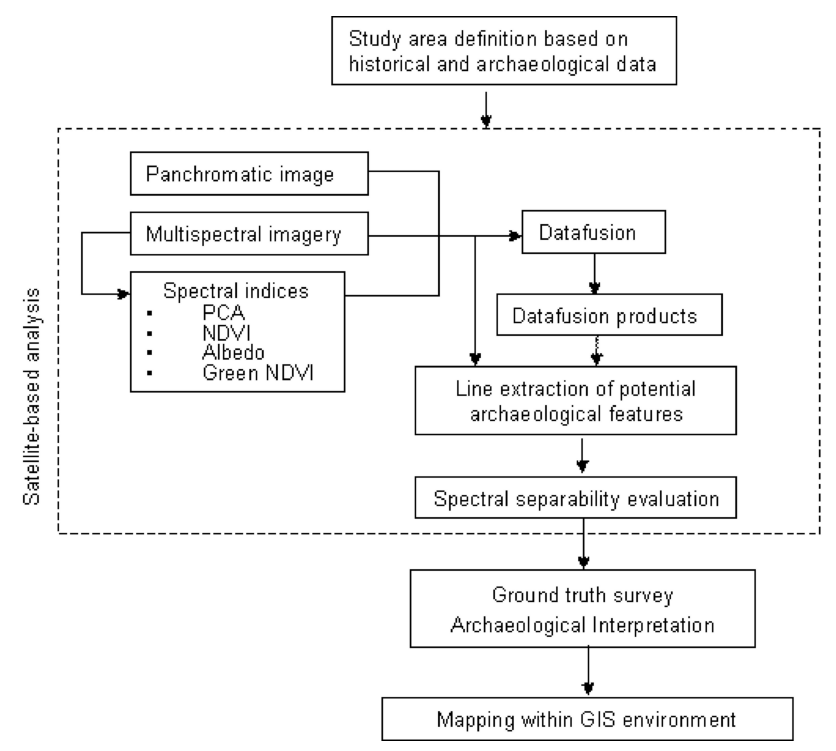

Fig. 2. Flowchart of the methodology.

Finally, a series of new image layers (called eigenchannels or components) are computed (Eq. 3) by multiplying, for each pixel, the eigenvector of $\mathbf{S}$ for the original value of a given pixel in the input bands.

$P_{i}=\sum_{i=1} P_{k} u_{k, i}$

where:

$P_{i}$ indicates a new image layer in component $i$,

$k$ is the number of input band,

$P_{k}$ is the spectral value for band $k$

$u_{k, i}$ is the eigenvector element for component $i$ in input band $k$,

A loading, or correlation $R$, of each component $i$ with each input channel $k$ can be calculated by using Eq. (4).

$R_{k, i}=u_{k, i}(\lambda i)^{\frac{1}{2}}\left(\operatorname{var}_{k}\right)^{\frac{1}{2}}$

where $\operatorname{var}_{k}$ is the variance of input channel $k$ (obtained by reading the $k^{\text {th }}$ diagonal of the covariance matrix).

The major portion of the variance in a multi-spectral data set is associated with the first component, whereas later components contain less of the total dataset variance. They may represent information variance for a small area or what is essentially noise and, in this case, it must be disregarded. Some problems can arise from the fact that eigenvectors cannot have a general and universal meaning since they are extracted from the series itself.

In order to enhance the presence of archaeological features, we also considered spectral indices obtained by combining different spectral bands. The spectral indices are 
Table 1. Site 1: Separability Spectral Indicators computed for the panchromatic, the image fused channel and the spectral indices products. The highest values of SSI are observed for red channel NDVI and PCA2.

\begin{tabular}{|c|c|c|c|c|c|c|c|c|c|}
\hline \multicolumn{2}{|c|}{ Hierapolis site 1} & \multicolumn{4}{|c|}{ mask pattern 1 (bitmap size $=4$ pix $)$} & \multicolumn{4}{|c|}{ mask pattern $2($ bitmap size $=2$ pix $)$} \\
\hline Channel/product & $*$ & $\mu$ & $\sigma$ & $\Delta \mu$ & $\mathrm{SSI}=\Delta \mu(\sigma 1+\sigma 2)$ & $\mu$ & $\sigma$ & $\Delta \mu$ & $\mathrm{SSI}=\Delta \mu(\sigma 1+\sigma 2)$ \\
\hline \multirow[t]{2}{*}{ 1-BLUE } & $\mathrm{F}$ & 57.3 & 3.09 & -1.8 & 0.294 & 55.1 & 2.61 & -4.1 & 0.743 \\
\hline & S & 59.1 & 3.03 & & & 59.2 & 2.91 & & \\
\hline \multirow[t]{2}{*}{ 2-GREEN } & $\mathrm{F}$ & 55.6 & 4.23 & -2.5 & 0.298 & 53.2 & 2.89 & -5.6 & 0.837 \\
\hline & S & 58.1 & 4.15 & & & 58.8 & 3.8 & & \\
\hline \multirow[t]{2}{*}{$3-\mathrm{RE}$} & $\mathrm{F}$ & 45.9 & 5.66 & -3.5 & 0.315 & 41.9 & 3.71 & -8 & 0.942 \\
\hline & $S$ & 49.4 & 5.46 & & & 49.9 & 4.78 & & \\
\hline \multirow[t]{2}{*}{ 4-NIR } & F & 94.4 & 4.44 & 1.2 & 0.145 & 94.8 & 3.11 & 1.3 & 0.213 \\
\hline & $S$ & 93.2 & 3.82 & & & 93.5 & 3 & & \\
\hline \multirow[t]{2}{*}{ 5-PAN } & $\mathrm{F}$ & 61.6 & 3.39 & -1.4 & 0.197 & 59.4 & 2.48 & -3.5 & 0.615 \\
\hline & $S$ & 63 & 3.73 & & & 62.9 & 3.21 & & \\
\hline \multirow[t]{2}{*}{ 6-NDVI } & $\mathrm{F}$ & 171.9 & 8.01 & 5 & 0.321 & 177 & 5.74 & 10.5 & 0.885 \\
\hline & S & 166.9 & 7.56 & & & 166.5 & 6.13 & & \\
\hline \multirow[t]{2}{*}{ 7-ALBEDO } & $\mathrm{F}$ & 116.5 & 5.26 & -1.9 & 0.189 & 113.5 & 3.2 & -5.6 & 0.712 \\
\hline & S & 118.4 & 4.79 & & & 119.1 & 4.66 & & \\
\hline \multirow[t]{2}{*}{ 8-SR } & $\mathrm{F}$ & 40.6 & 5.93 & 3.5 & 0.316 & 44.4 & 5.03 & 7.7 & 0.831 \\
\hline & S & 37.1 & 5.15 & & & 36.7 & 4.24 & & \\
\hline \multirow[t]{2}{*}{ 9-Green NDVI } & F & 160.6 & 5.91 & 3.4 & 0.300 & 163.5 & 4.33 & 6.7 & 0.769 \\
\hline & S & 157.2 & 5.41 & & & 156.8 & 4.38 & & \\
\hline \multirow[t]{2}{*}{ 10-PCA1 } & $\mathrm{F}$ & 136 & 4.82 & 2 & 0.211 & 138.8 & 3.08 & 5.5 & 0.723 \\
\hline & $S$ & 134 & 4.66 & & & 133.3 & 4.53 & & \\
\hline \multirow[t]{2}{*}{ 11-PCA2 } & $\mathrm{F}$ & 114.6 & 10.99 & -6.8 & 0.319 & 108.2 & 7.96 & -13.7 & 0.839 \\
\hline & S & 121.4 & 10.3 & & & 121.9 & 8.36 & & \\
\hline \multirow[t]{2}{*}{ 12-PCA3 } & F & 130.5 & 9.44 & 3.7 & 0.214 & 134.9 & 6.56 & 9.1 & 0.716 \\
\hline & $S$ & 126.8 & 7.87 & & & 125.8 & 6.15 & & \\
\hline \multirow[t]{2}{*}{ 13-PCA4 } & F & 133.7 & 10.17 & -0.7 & 0.035 & 139.7 & 10.28 & 1.8 & 0.096 \\
\hline & S & 134.4 & 9.57 & & & 137.9 & 8.55 & & \\
\hline
\end{tabular}

* F: features; S: surrounding

quantitative measures of surface properties; they attempt to quantify brightness, moisture, biomass cover, or vegetative vigour. Usually, the numerator is a spectral band characterized by a high reflective energy for the given material, whereas the denominator is a band covering an absorption feature. In particular, vegetation indices are mainly derived as a ratio between near-infrared and red reflectance.

Equation 5 is the simple ratio SR calculated using NIR and RED bands. SR values for bare soils generally are near 1; as the amount of green vegetation increases in a pixel the SR increases. Generally, very high SR values are around 30.

$\mathrm{SR}=\rho \mathrm{NIR} / \rho \mathrm{RED}$

One of the most widely used indices is the Normalized Difference Vegetation index (NDVI) obtained by using the following equation:

$\mathrm{NDVI}=(\rho \mathrm{NIR}-\rho \mathrm{RED}) /(\rho \mathrm{NIR}+\rho \mathrm{RED})$

The NDVI operates by contrasting intense chlorophyll pigment absorption in the red against the high reflectance of leaf mesophyll in the near infrared. The normalization of the NDVI reduces the effects of variations caused by atmospheric contamination.

The NDVI is indicative of plant photosynthetic activity and has been found to be related to the green leaf area index and to the fraction of photosynthetically active radiation absorbed by vegetation. High values of the vegetation index identify pixels covered by substantial proportions of healthy vegetation, whilst disease or stressed vegetation exhibits lower NDVI values.

The NDVI has been successfully used in archaeological applications to enhance crop marks for both homogeneous vegetation covers (Lasaponara and Masini, 2006) and sparse herbaceous plants (Masini and Lasaponara, 2006).

The calculation of the NDVI value could be sensitive to a number of perturbing factors including atmospheric, cloud, soil, and anisotropic effects. A number of derivatives or alternatives to NDVI have been proposed in the scientific literature to address these limitations. In this paper, we consider the "Green"NDVI, obtained from Eq. 7. The "Green"NDVI. 
Table 2. Site 2: Separability Spectral Indicators computed for the panchromatic, the image fused channel and the spectral indices products. The highest values of SSI are observed for panchromatic, PCA1 and Albedo.

\begin{tabular}{|c|c|c|c|c|c|c|c|c|c|}
\hline \multicolumn{2}{|c|}{ Hierapolis site 2} & \multicolumn{4}{|c|}{ mask pattern 1 (bitmap size $=4$ pix $)$} & \multicolumn{4}{|c|}{ mask pattern $2($ bitmap size $=2$ pix $)$} \\
\hline Channel/product & $*$ & $\mu$ & $\sigma$ & $\Delta \mu$ & $\mathrm{SSI}=\Delta \mu(\sigma 1+\sigma 2)$ & $\mu$ & $\sigma$ & $\Delta \mu$ & $\mathrm{SSI}=\Delta \mu(\sigma 1+\sigma 2)$ \\
\hline \multirow[t]{2}{*}{ 1-BLUE } & $\mathrm{F}$ & 53.9 & 1.73 & 0.5 & 0.154 & 54 & 2.15 & 0.2 & 0.049 \\
\hline & S & 53.4 & 1.51 & & & 53.8 & 1.9 & & \\
\hline \multirow[t]{2}{*}{ 2-GREEN } & $\mathrm{F}$ & 50.6 & 1.95 & 1.2 & 0.334 & 50.8 & 2.13 & 0.7 & 0.174 \\
\hline & S & 49.4 & 1.64 & & & 50.1 & 1.9 & & \\
\hline \multirow[t]{2}{*}{$3-\mathrm{RE}$} & $\mathrm{F}$ & 39.7 & 2.22 & 0.8 & 0.186 & 39.4 & 2.83 & 0.4 & 0.072 \\
\hline & $S$ & 38.9 & 2.08 & & & 39 & 2.75 & & \\
\hline \multirow[t]{2}{*}{ 4-NIR } & $\mathrm{F}$ & 85.6 & 6.3 & 3.7 & 0.310 & 87 & 5.41 & 2.5 & 0.220 \\
\hline & $S$ & 81.9 & 5.63 & & & 84.5 & 5.96 & & \\
\hline \multirow[t]{2}{*}{ 5-PAN } & $\mathrm{F}$ & 56.5 & 2.85 & 2.7 & 0.480 & 56.9 & 2.24 & 2.2 & 0.422 \\
\hline & S & 53.8 & 2.77 & & & 54.7 & 2.97 & & \\
\hline \multirow[t]{2}{*}{ 6-NDVI } & $\mathrm{F}$ & 174.2 & 5.63 & 1.2 & 0.109 & 175.6 & 5.95 & 1 & 0.081 \\
\hline & S & 173 & 5.34 & & & 174.6 & 6.33 & & \\
\hline \multirow[t]{2}{*}{ 7-ALBEDO } & $\mathrm{F}$ & 104.1 & 5 & 3.9 & 0.408 & 104.9 & 4.24 & 2.4 & 0.271 \\
\hline & S & 100.2 & 4.56 & & & 102.5 & 4.63 & & \\
\hline \multirow[t]{2}{*}{ 8-SR } & $\mathrm{F}$ & 42.1 & 4.76 & 1 & 0.110 & 43.2 & 5.11 & 0.8 & 0.076 \\
\hline & S & 41.1 & 4.35 & & & 42.4 & 5.36 & & \\
\hline \multirow[t]{2}{*}{ 9-Green NDVI } & $\mathrm{F}$ & 160.3 & 4.8 & 1.2 & 0.132 & 161 & 4.96 & 1 & 0.100 \\
\hline & S & 159.1 & 4.32 & & & 160 & 5.01 & & \\
\hline \multirow[t]{2}{*}{ 10-PCA1 } & $\mathrm{F}$ & 147.1 & 4.2 & -3.4 & 0.421 & 146.1 & 3.46 & -2.2 & 0.306 \\
\hline & S & 150.5 & 3.88 & & & 148.3 & 3.72 & & \\
\hline \multirow[t]{2}{*}{ 11-PCA2 } & $\mathrm{F}$ & 113.8 & 8.33 & -2.3 & 0.147 & 112.3 & 8.65 & -1.7 & 0.097 \\
\hline & S & 116.1 & 7.27 & & & 114 & 8.86 & & \\
\hline \multirow[t]{2}{*}{ 12-PCA3 } & $\mathrm{F}$ & 143.4 & 8.67 & -3.5 & 0.218 & 144.5 & 7.69 & -2.6 & 0.160 \\
\hline & S & 146.9 & 7.42 & & & 147.1 & 8.59 & & \\
\hline \multirow[t]{2}{*}{ 13-PCA4 } & $\mathrm{F}$ & 134 & 9.93 & 3.7 & 0.203 & 136.8 & 11 & 3.4 & 0.185 \\
\hline & S & 130.3 & 8.28 & & & 133.4 & 7.41 & & \\
\hline
\end{tabular}

* F: features; S: surrounding

exhibits a wider range than the original NDVI and is, on average, at least five times more sensitive to chlorophyll concentration.

“Green”NDVI $=(\rho$ NIR $-\rho$ GREEN $) /(\rho$ NIR $+\rho$ GREEN $)$

where $\rho$ NIR and $\rho$ GREEN are the reflectance in NIR and green channel respectively.

Results of several studies (see for example, Gitelson and Merzlyak, 1996) pointed out that the maximum sensitivity of reflectance coincides with the maximum absorption of chlorophyll for a wide range of leaf greenness (from completely yellow to dark green leaves).

Finally, we also consider albedo, computed from Eq. 8. The albedo is an indicator of the surface darkness. The empirical approximation of the surface albedo was provided by Saunders (1990):

$\mathrm{ALBEDO}=(\rho \mathrm{NIR}+\rho \mathrm{RED}) / 2$

where $\rho$ NIR and $\rho$ RED are the reflectance in NIR and red channel, respectively.
Albedo is referred to the measure of a given land surface to reflect solar radiation back towards space. Albedo is the ratio of the amount of solar radiation reflected from a surface to the total amount reaching that surface. Surface materials that appear to be light-coloured in the visible spectrum have generally high solar reflectance. Whereas dark-coloured materials have low solar reflectance. Snow, for instance, has a high albedo because it reflects higher than $85 \%$ of incoming sunlight. While vegetation and dark soil reflect less than $20 \%$. The solar radiation reaching an object on earth includes visible and ultraviolet light and infrared radiation. For application in archaeological context, it is expected that variation in the colour and composition of the surface material could be better appreciated using albedo than single spectral channel.

In this study, in order to evaluate the capability of the available data set, the investigations were performed considering both single spectral channels and their numerical combinations. All of them were first investigated individually and then combined by using a data fusion algorithm to integrate 


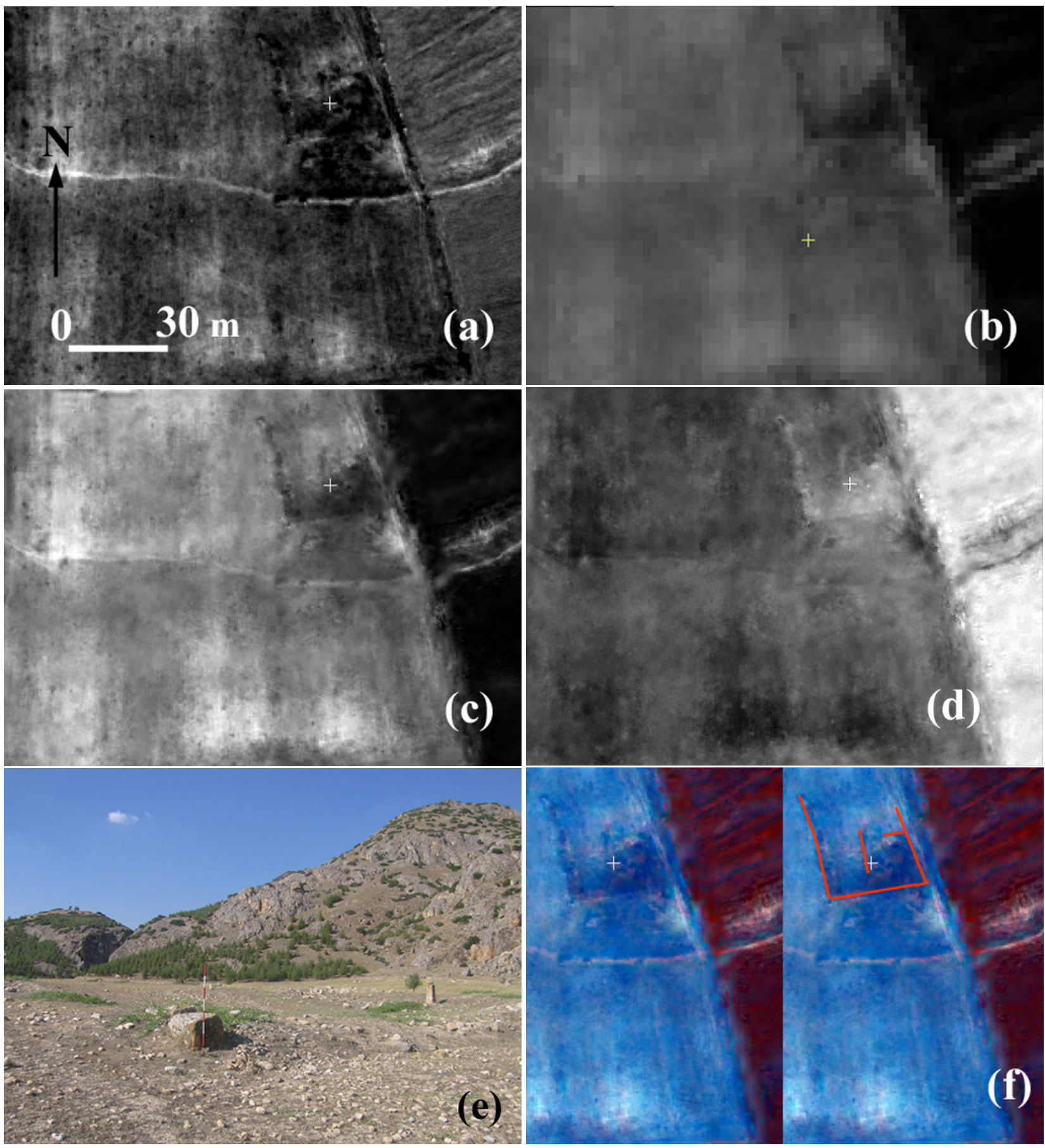

Fig. 3. Site 1: image processing, ground truth and archaeological reconnaissance which allowed to discover a farm dating back between the early Imperial Roman and the proto-Byzantine age. In particular: (a) panchromatic image; (b) red channel image (2.40 m); (c) red data fusion product; (d) PCA2 product; (e) photo of the site which put in evidence micro-relief traces (shadow-marks) and soil marks produced by incoherent surfacing materials (tiles and pottery); (f) RGB composition ( $R=$ pan; $G=$ red; $B=\mathrm{PCA} 2$ ) and survey of marks of archaeological interest. 

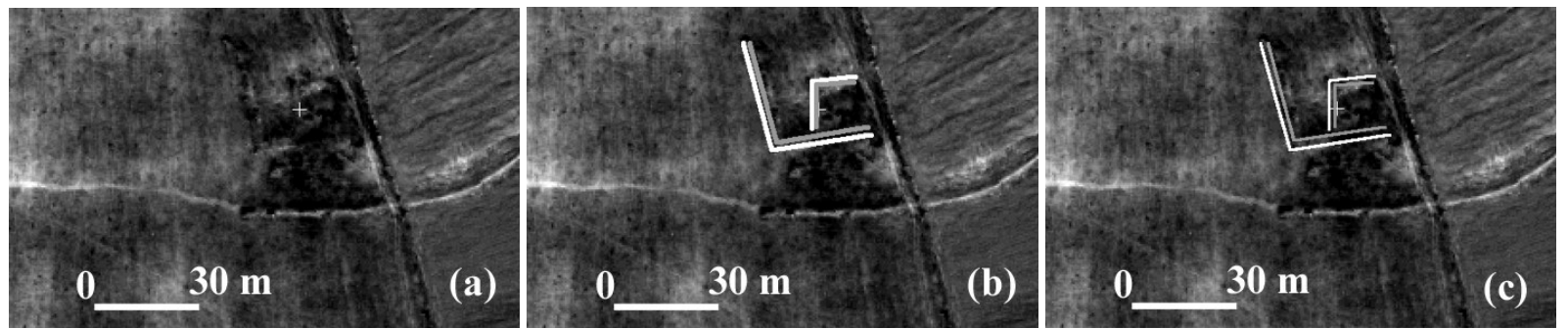

Fig. 4. (a) panchromatic image of site 1, (b-c) with two mask patterns, 1 and 2 (see Table 1), respectively with size of 4 and 2 . For each channel and enhancement product SSI between features (bright tone mask) and their surrounding (dark tone mask) has been computed.
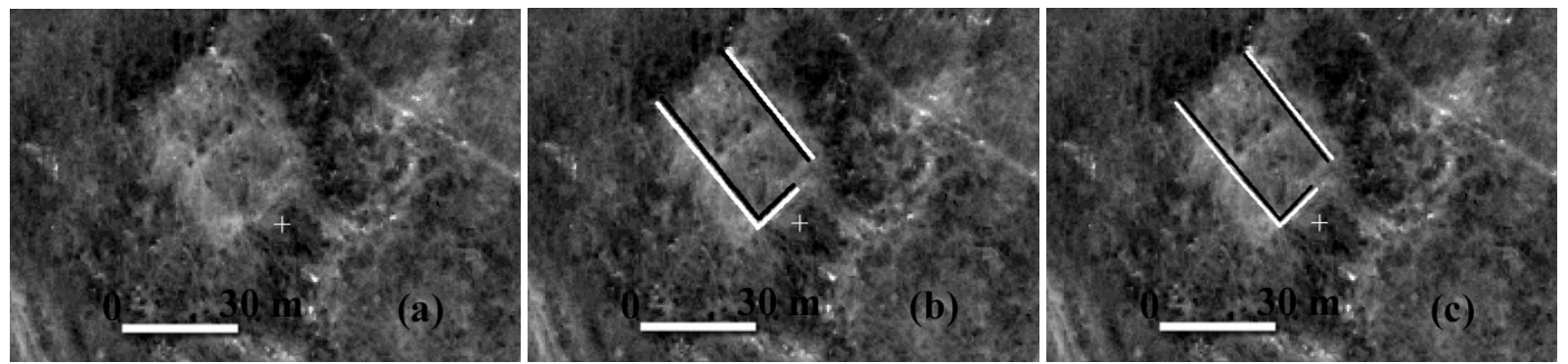

Fig. 5. (a) panchromatic image of site 2, (b-c) with two mask patterns, 1 and 2 (see Table 2), respectively with size of 4 and 2 , for which SSI has been assessed. For each channel and enhancement product SSI between features (bright tone mask) and their surrounding (dark tone mask) has been computed.

the geometric detail of the panchromatic with the spectral information of the multispectral images.

Panchromatic, image fused channels, and the spectral indices including the PCA components were numerically evaluated by using a specific indicator, called Spectral Separability Index (SSI) (Masini and Lasaponara, 2006). The SSI is computed considering the contrast between the archaeological features and their surroundings. It is computed by Eq. 9:

$\mathrm{SSI}=\Delta \mu\left(\sigma_{1}+\sigma_{2}\right.$

where $\Delta \mu, \sigma_{1}, \sigma_{2}$ are respectively the average spectral differences and standard deviation observed for two masks, one referred to archaeological features and the second related to their surrounding.

\section{Results}

The analysis of satellite Quickbird data has allowed us to detect signs of intensive occupation of the territory. A number of potential archaeological evidence has been identified, analyzed and verified by the field survey. This has contributed to a detailed reconstruction of the historical development of the territory from prehistoric times to the modern period. In this paper, we focus on the Imperial Roman to the Byzantine age. Relating to this period, several rural settlements (farms) were found in a large area around Hierapolis. During the Roman and Byzantine periods the whole area and its settlements were under the administration of the city. Some of these farms were constructed with small blocks extracted from nearby travertine quarries. On the ground the visible remains of these ancient farms were sometimes negligible, but the processing of the satellite images highlighted the traces of buried walls. External perimeter and internal structures of the ancient buried edifices were successfully identified and spatially characterized by Quickbird images. In this paper we focus on two test sites (herein indicated as 1 and 2) which are detailed in Sects. 4.1 and 4.2.

\subsection{Site 1: remote sensing data and in situ archaeological survey}

Test site 1 is located at around $2 \mathrm{~km}$ North of Hierapolis (see Fig. 1) in a bare area sparsely covered by spontaneous plants of medium height. Due to the absence of significant vegetation cover, only the panchromatic and red channel allowed us to discriminate spatial anomalies of potential archaeological interest; thus confirming the results obtained in similar sites in Southern Italy (Masini and Lasaponara, 2006). Figure 3a$\mathrm{b}$ show QuickBird panchromatic and red channel at spatial resolution of $0.6 \mathrm{~m}$ and $2.4 \mathrm{~m}$ respectively. The red data fusion product $(0.6 \mathrm{~m})$ better enhances archaeological marks related to a potential buried building with a rectangular shape 

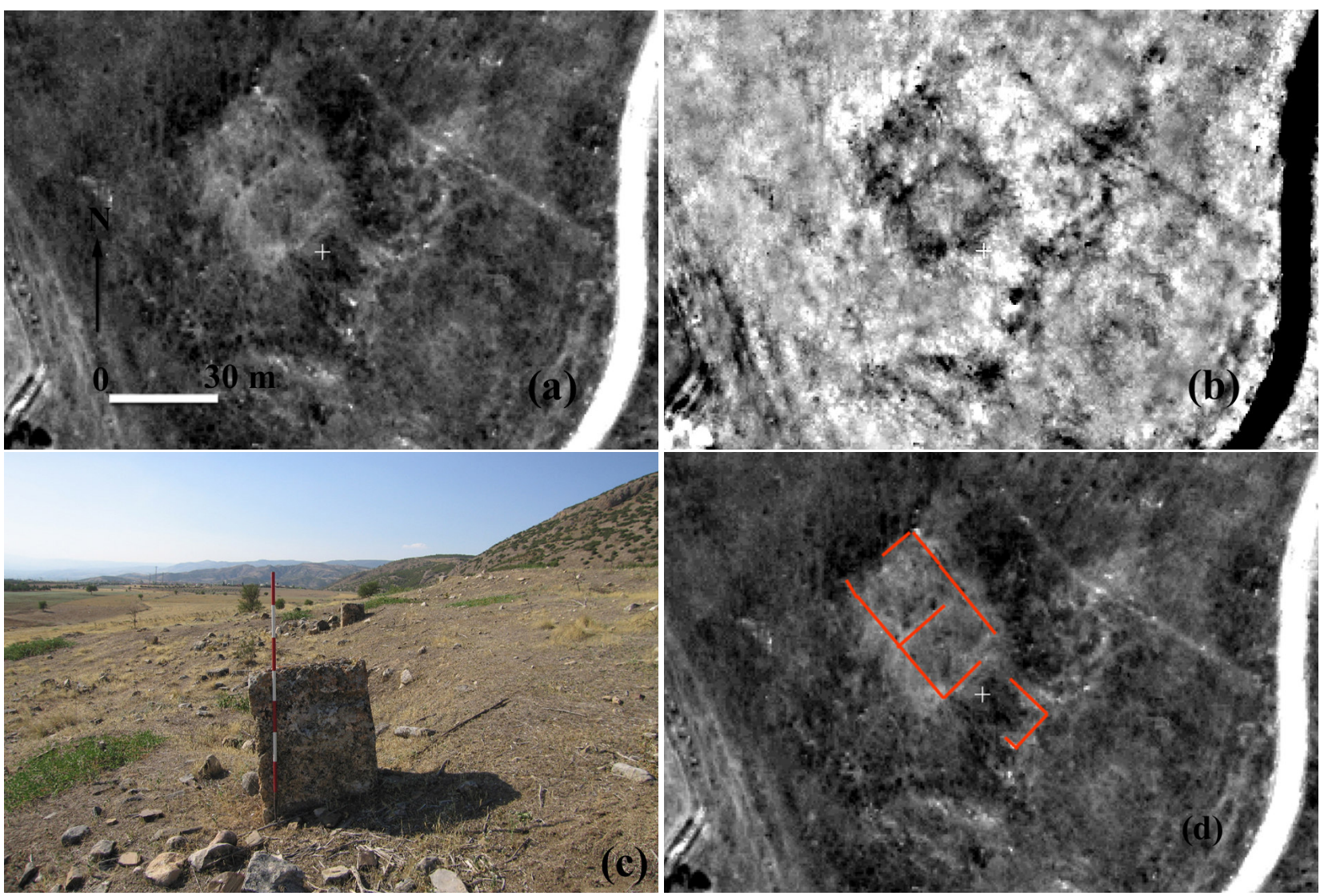

Fig. 6. Site 2: image processing, ground truth and archaeological reconnaissance which allowed to discover a farm dating back between the early Imperial Roman and the proto-Byzantine age. In particular: (a) panchromatic image; (b) PCA1 product; (c) photo of the site; (f) panchromatic image with marks of archaeological interest which allowed to reconstruct the plan of the ancient farm.

of about $25 \times 20 \mathrm{~m}$. (see Fig. 3c). A significant enhancement of these marks was obtained by using the PCA (see Fig. 3d) and the spectral indices (Eqs. 5 to 8 ). Figure 3 f shows an RGB composition ( $R=$ pan; $G=$ red; $B=$ PCA2) and archaeological marks that were confirmed by in situ analysis (see Fig. 3e).

The capability of the considered data set (panchromatic, multispectral channel, PCA and spectral indices) was assessed in a quantitative way by using the SSI computed using Eq. 9 (in Sect. 3.2). Higher SSI values indicate higher spectral separability of the archaeological features compared to their background. The evaluation was performed for two different masks: (i) one having a width size of two pixels (Fig. 4b) and (ii) the second having a width size of four pixels (Fig. 4c). Table 1 shows the SSI values (the most significant results are in bold). The SSI values obtained from the two masks are in accordance with each other. In particular, the higher values of SSI are obtained from red, NDVI and the second PCA component.

The field survey confirmed the archaeological interest of the detected features and allowed us to characterize them.
In particular on the eastern side, the field survey put in evidence that the identified archaeological marks were microrelief traces (shadow-marks) that appeared to be in connection with some stone elements partly exposed on the surface (such as a jamb of a door).

Whereas, the western side was characterized by soil-marks produced by incoherent surfacing materials (tiles and pottery). Between the western and eastern sides a slight depression was observed on the ground. It was probably referable to a court or a large store for agricultural products (with big dolia).

In the middle of the southern side of the edifice, a threshold of a door $(1.65 \mathrm{~m}$. large) was found. The photo in Fig. 3e shows micro-relief traces (shadow-marks) and soil marks produced by incoherent surfacing materials (tiles and pottery).

In conclusion, the integration of the QuickBird data processing with ground truth allowed us to reconstruct the plan of buried structures referable to a farm, dating back to a period between Imperial Roman and the early Byzantine age. 
4.2 Site 2: remote sensing data and in situ archaeological survey

Another buried building, here indicated as site 2, was also discovered by means of the integration of satellite and field survey. The area of archaeological interest is situated on a slight relief about $450 \mathrm{~m}$. North to the necropolis of Hierapolis (Fig. 1). The site exhibits surface characteristics similar to those observed for site 1.

The processing of Quickbird images was performed, as in the case of site 1, according to the flow chart shown in Fig. 2. Panchromatic, single channels, data fusion products, PCA components and spectral indices were analysed. The capability of the considered data set was assessed in a quantitative way by using the SSI computed for two different masks (1 and 2) having different width sizes (four and two pixels respectively) as previously performed for site 1 (see Fig. 5ac). Table 2 shows the SSI values for both the two considered masks. The SSI computed for the panchromatic is much higher than the SSI values computed for all the other imagery (see Table 2 and Fig. 6a). Significant results were only obtained from the first PCA component (Fig. 6b). This is in perfect accordance with the fact that the first PCA component provides a map very close to the brightness and similar to the panchromatic scene.

The panchromatic was used to discriminate potential archaeological features. The detected features were related to (i) the perimeter of a buried building, having a rectangular shape $(38 \mathrm{~m}$ long and $22 \mathrm{~m}$ wide in the South-East/NorthWest direction); (ii) an internal division inside the same building and (iii) other potential features located on the Southeast side probably referable to buried structures.

The ground truth confirmed the archaeological interest of the identified features (Fig. 6c-d). In particular, the features related to the perimeter of the building were the typical micro-relief anomalies (shadow marks). Whereas, the internal division was given by remains of a wall visible on the surface by a few centimetres.

Finally, the finding of fragments of travertine blocks, tiles, coarse ware and dolia permitted us to attribute the building to a farm and to date it to a period between Imperial Roman and the early Byzantine age.

\section{Conclusions}

In this paper satellite QuickBird images were used to support archaeological investigations in the ancient territory of Hierapolis of Phrygia in the South East of Turkey. Pan sharpening, spectral indices and PCA were adopted to enhance the archaeological features. Two rural farms dating back to the Hellenistic to the Byzantine age were found around Hierapolis. The ground truth confirmed the archaeological interest of the detected features.
The capability of the considered data set (panchromatic, multispectral channel, PCA and spectral indices) in detecting archaeological features was assessed in a quantitative way by using a specific indicator.

Results from the numerical evaluation showed that: (i) Soil marks were better discriminated by the red data fusion product, the second PCA component and NDVI; (ii) panchromatic image was able to better enhance shadow marks.

Acknowledgements. For his constant support and the great interest with which he has followed the topographical research in the urban area and in the territory of Hierapolis, we thank Francesco D'Andria, Director of the Italian Archaeological Mission in Hierapolis and of IBAM-CNR. The surveys on the ground in the campaigns of 2003-2004 would not have been possible without the help and the collaboration of Pierpaolo Nardelli and Paolo Ciuchini; special thanks go to Laura Castrianni and Giacomo Di Giacomo, who have been working from 2005 on the research project finalized to the realization of the archaeological maps of Hierapolis and its territory.

Edited by: L. V. Eppelbaum

Reviewed by: three anonymous referees

\section{References}

Altaweel, M.: The use of aster satellite imagery in archaeological contexts, Archaeol. Prospect., 12, 151-166, 2005.

Beck, A., Philip, B., Abdulkarim, M., and Donoghue, D.: Evaluation of Corona and Ikonos satellite imagery for archaeological prospection in western Syria, 81, 161-175, 2007.

Behnaz, A. and Samani, F.: Identifying the boundaries of the historical site of Persepolis using remote sensing, Remote Sens. Environ., 102, 252-62, 2006.

Clark, C. D., Garrod, S. M., and Parker Pearson, M.: Landscape archaeology and Remote Sensing in southern Madagascar, Int. J. Remote Sens., 19(8), 1461-1477, 1998.

D'Andria, F.: Hierapolis di Frigia (Pamukkale), Guida archeologica, Ege Yaynlari, Istanbul 2003.

D’Andria, F. and Caggia, M. P.: Hierapolis di Frigia, I. Le attività delle campagne di scavo e restauro 2000-2003, Ege Yaynlari, Istanbul, 2007.

D'Andria, F., Scardozzi, G., and Spanò, A.: Atlante di Hierapolis di Frigia, Ege Yaynlari, Istanbul, 2008.

De Laet, V., Paulissen, E., and Waelkens, M.: Methods for the extraction of archaeological features very high-resolution Ikonos-2 remote sensing imagery, Hisar (southwest Turkey), J. Archaeol. Sci., 34(2007), 830-841, 2006.

Fowler M. J. F.: Satellite Remote Sensing and Archaeology: a comparative study of satellite imagery of the environs of Figsbury Ring, Wiltshire Archaeological Prospection, 9, 55-69, 2002.

Gitelson, A. A. and Merzlyak, M. N.: Relationships between leaf chlorophyll content and spectral reflectance and algorithms for non-destructive chlorophyll assessment in higher plant leaves, J. Plant Physiol., 148(3-4), 494-500, 1996.

Goossens, R., De Wulf, A., Bourgeois J., Gheyle, W., and Willems, T.: Satellite imagery and archaeology: the example of CORONA in the Altai Mountains, J. Archaeol. Sci., 33, 745-755, 2006. 
Lasaponara, R. and Masini, N.: QuickBird-based analysis for the spatial characterization of archaeological sites: case study of the Monte Serico Medioeval village, Geophys. Res. Lett., 32(12), L12313, doi:10.1029/2005GL022466, 2005.

Lasaponara, R. and Masini, N.: Identification of archaeological buried remains based on Normalized Difference Vegetation Index (NDVI) from Quickbird satellite data, IEEE Transactions on Geoscience and Remote Sensing Letters, 3(3), 325-328, 2006.

Lasaponara, R. and Masini, N.: Detection of archaeological crop marks by using satellite QuickBird, J. Archaeol. Sci., 34, 214 221, 2007.

Masini, N. and Lasaponara, R.: Evaluation of the spectral capability of quickbird imagery for the detection of archaeological buried remains, in: Space to place, edited by: Campana, S. and Forte, M., Proceedings of 2nd International Conference on Remote Sensing in Archaeology (Rome, 4-7 December 2006), BAR International Series, 21-29, 2006.
Parry, J. T.: The investigative role of Landsat TM in the examination of pre-proto-historic water management sites in northeast Thailand Geocarto Int., 4, 5-24, 1992.

Richards, J. A.: Remote sensing digital image analysis: an introduction, Berlin, New York, Springer, p. 363, 1999.

Scardozzi, G.: L'urbanistica di Hierapolis di Frigia: ricerche topografiche, immagini satellitari e fotografie aeree, in Archeologia Aerea, Studi di Aerotopografia Archeologica, II, 83-124, 2007.

Scardozzi, G.: Remote sensing and archaeological survey in the Hierapolis of Phrygia territory, Turkey, in Remote Sensing for Environmental Monitoring, GIS Applications and Geology, Conference 6749 "Remote Sensing and Archaeology", Proceedings of SPIE Europe Remote Sensing (Florence 17-20 September 2007), 6749, 674904/1-12, 2007.

Wilson, D. R.: Air photo interpretation for archaeologists (London: St. Martin's Press), 1982. 